\title{
Avaliação microbiológica de secadores de mãos elétricos em banheiros de uso comum
}

\section{Microbiological evaluation of electric hand dryers in bathrooms of common use}

Ivaldo Francisco da Silva Júnior ${ }^{1}$, Dárcio Luiz de Sousa Júnior², Tassia Thais Al Yafawi, Pedro Everson Alexandre de Aquino ${ }^{3 *}$, Jailson de Castro Freitas ${ }^{4}$, Livia Maria Garcia Leandro ${ }^{5}$, Sarah de Sousa Ferreira ${ }^{6}$, Rakel Olinda Macedo da Silva

${ }^{1}$ Biomédico, Centro Universitário Dr. Leão Sampaio, Juazeiro do Norte, Ceará, Brasil. https://orcid.org/0000-0001-6951-4342 E-mail: franciscojuc@hotmail.com

${ }_{2}^{2}$ Biomédico, Universidade Regional do Cariri, Departamento de Química Biológica, Laboratório de Bioprospecção do Semiárido, Crato, Ceará, Brasil - https://orcid.orq/0000-0002-1539-9267 E-mail: darciolsjr@gmail.com

${ }^{3}$ Biomédico, Universidade Maurício de Nassau, Fortaleza, Ceará, Brasi. https://orcid.org/0000-0002-4756-081X E-mail: pedroeverson.alexandre@gmail.com *Autor de correspondência

${ }^{4}$ Enfermeiro, Universidade Maurício de Nassau, Fortaleza, Ceará, Brasi. https://orcid.org/0000-0001-7223-4365 E-mail: jailsonpucsp@gmail.com

${ }^{5}$ Biomédica, Centro Universitário Dr. Leão Sampaio, Juazeiro do Norte, Ceará, Brasil. https://orcid.org/0000-0002-2259-9208 E-mail: livialeandro@leaosampaio.edu.br

${ }^{6}$ Biomédica, Universidade Federal do Rio Grande do Norte, Natal, Rio Grande do Norte, Brasil. https://orcid.org/0000-0002-3268-4270 Email: sarahferreira@ufrn.edu.br

${ }^{7}$ Biomédica, Centro Universitário Dr. Leão Sampaio, Juazeiro do Norte, Ceará, Brasil. https://orcid.org/0000-0002-6298-8996 E-mail: rakelolinda@leaosampaio.edu.br

\section{Palavras-chave}

Bactérias

Contaminação

Secadores de mão
O secador de mãos elétrico se tornou cada vez mais presente em vários estabelecimentos públicos e privados, $e$ mesmo inseridos positivamente no meio social, pouco é conhecido sobre o potencial microbiológico exposto aos usuários. Objetivo: Nesse contexto, o objetivo deste trabalho é avaliar o índice de contaminação microbiológica de secadores de mãos de uso comum. Metodologia: A coleta de amostras foi realizada em campus de uma universidade particular no interior do Ceará, onde swabs foram umedecidos com solução de $\mathrm{NaCl}$, sendo os mesmos friccionados no interior dos secadores e inoculados em meio Brain Heart Infusion (BHI), e em posterior semeados nos Agar Eosin Menthyilene Blue (EMB), Manitol, Salmonella-Shiguella (SS) e Agar Sangue. Resultados: Após o tempo determinado, foi observado o crescimento de colônias onde foram inoculados $e$ identificados por meios bioquímicos de acordo com o Manual de Identificação de Bactérias de Interesse Médico. Foram identificados Staphylococcus aureus, Staphylococcus coagulase-negativa, Bacillus sp., Streptococcus sp., Escherichia coli, Pseudomonas aeruginosa e Fungos, sendo a S. aureus presente em todos os secadores. Ainda, os banheiros masculinos apresentaram um maior nível de contaminação. Conclusão: Pode-se concluir que a contaminação em secadores de mãos é evidente, podendo colocar a saúde dos seus usuários em risco. Portanto, medidas de controle e limpeza desses equipamentos são de suma importância para evitar riscos de contaminação.

\section{Keywords}

Bacteria

Contamination

Hand dryers
The electric hand dryer has become increasingly present in several public and private establishments, and even inserted positively in the social environment, little is known about its microbiological potential exposed to users. objective: In this context, the aim this paper is evaluate the microbiological contamination index of hand dryers in common use. Methodology: The collection of samples was carried out on the campus of a private university in the interior of Ceará, where swabs were moistened with $\mathrm{NaCl}$ solution, the same being rubbed inside the dryers and inoculated in Brain Heart Infusion (BHI), and later sown on Eosin Menthyilene Blue Agar (EMB), Mannitol, Salmonella-Shiguella (SS) and Blood Agar (BA). Results: After the determined time, the growth of colonies were observed where they were inoculated and identified by biochemical means according to the Manual of Identification of Bacteria of Medical Interest. Were identified Staphylococcus aureus, Staphylococcus coagulase-negative, Bacillus sp., Streptococcus sp., Escherichia coli, Pseudomonas aeruginosa and Fungi, with S. aureus present in all dryers. In addition, men's bathrooms showed a higher level of contamination. Conclusion: In conclusion, that contamination in hand dryers is evident, which can put the health of its users at risk. Therefore, control and cleaning measures for this equipment are of paramount importance to avoid risks of contamination. 


\section{INTRODUÇÃO}

O ar atmosférico é composto por alguns componentes como vapor d'água, gases e principalmente microrganismos e impurezas (fuligens e poeira). Atualmente vem crescendo a atenção sobre a qualidade microbiológica do ar, pois com o passar dos anos as pessoas estão passando mais tempo em ambientes fechados (VIRTUOUS, 2016).

As prováveis impurezas do ar de ambientes internos podem decorrer da má ventilação, alastramento de partículas, sujidades por equipamentos voláteis e comumente por contaminação, sendo esses agentes infecciosos os fungos, bactérias e vírus que ainda em pequenas quantidades podem causar uma enorme preocupação (JONES; GAO, 2013).

O secador de mãos elétrico está cada vez mais presente em estabelecimentos públicos e privados, e, mesmo inseridos positivamente no meio social, pouco é conhecido sobre seu potencial microbiológico. Quando utilizados esses microrganismos podem ser expostos aos usuários, podendo ocasionar problemas de saúde devido a sua capacidade de disseminação (RAMOS; FILHO; LOBO, 2017).

Ao acionar uma descarga com a tampa do sanitário aberta, partículas de coliformes e outros variados tipos de microrganismos são propagados no ar. Assim, ao ser acionado, o secador pode sugar essas partículas e espalhalas mais ainda sobre o ambiente e mãos do usuário. Ainda, o interior desse equipamento é quente e pode ser úmido, o que facilita a proliferação das células presentes naquele local (SANTOS; 2011; ESPITÍA, 2018).

Estudos recentes demonstraram que a contagem de bactérias feita nas mãos de participantes que secaram no equipamento aumentou em 4,5 vezes quando comparado a secagem realizada com papel toalha (BEST; PARNELL; WILCOX, 2014). Dessa forma é de extrema importância a obtenção de dados no que diz respeito a contaminação e proliferação bacteriana em secadores de mãos, visto que, o equipamento pode tornar-se veículo de relevantes microrganismos o que pode trazer danos à saúde dos usuários.

Deste modo, o presente estudo tem como objetivo avaliar a contaminação microbiológica em secadores de mãos elétricos de uso comum, presentes em banheiros masculinos e femininos de alguns campus universitários, a fim de avaliar o potencial risco à saúde que a utilização desses equipamentos podem ocasionar.

\section{MATERIAL E MÉTODOS}

\section{Local de coleta das amostras}

A coleta das amostras foi realizada em banheiros femininos e masculinos de três campus universitários localizados na cidade de Juazeiro do Norte no Ceará, Brasil.

\section{Coleta das amostras}

Em cada campus foram selecionados 10 secadores de mãos, sendo 5 localizados em banheiros masculinos e 5 femininos. Portanto, na totalidade foram utilizadas amostras de 30 secadores de mãos. Cada aparelho foi registrado com o número de fabricação, a fim de facilitar a análise dos dados, e também separados por localização e banheiros de acordo com a identidade de gênero.

Os critérios de inclusão utilizados no estudo foram: coleta somente nos períodos letivos e em horários de pico (7:30 às 12:00 horas e de 18:00 às 22:00 horas). Foram excluídos das análises secadores nos quais encontravam-se inativos.

O material foi coletado utilizando swabs estéreis. Antes das coletas os swabs foram umedecidos em solução salina estéril e inseridos na região de emissão de vapor dos secadores, sendo friccionados sobre essa superfície, visando coletar o máximo de sujidade presente no local. Posteriormente a amostra foi inoculada em tubos de ensaio contendo $3 \mathrm{~mL}$ de meio BHI (Brain Heart Infusion) 10\%.

\section{Processamento do material e identificação bacteriana}

Após a coleta, as amostras foram condicionadas e encaminhadas dentro de caixas de isopor com bandejas de gelo e para análise no Laboratório de Microbiologia do Centro Universitário Leão Sampaio (UNILEÃO), onde foram realizadas as identificações dos agentes patogênicos presentes.

As mesmas foram incubadas em estufa bacteriológica por 24 horas a $37^{\circ} \mathrm{C}$. Posteriormente, alíquotas de $0,1 \mathrm{~mL}$ foram semeadas nas superfícies dos meios de cultura EMB (Eosin Menthyilene Blue), Agar SS (Salmonella- Shiguella), Agar Manitol e Agar Sangue onde, com auxílio de uma alça de platina, as amostras foram semeadas utilizando a técnica de semeadura em esgotamento.

A identificação das bactérias isoladas foi feita de acordo com o Manual de Identificação de Bactérias de Interesse Médico (BRASIL, 2004). Para tanto, foram utilizados os meios de Fenil Alanina, Ureia, Citrato, ágar TSI (Triple Sugar Iron Agar) e SIM (Sulfito de Hidrogênio, Indol e Motilidade). Este método é internacionalmente reconhecido e padronizado para a identificação de bactérias de importância médica, permitindo diagnosticar todas as bactérias com probabilidade de serem encontradas em laboratórios clínicos, na prática médica. 


\section{Análise estatística}

Os dados foram organizados e tabulados no programa Excel 2013. E os gráficos foram gerados utilizando o programa GraphPad Prism 6.0.

\section{RESULTADOS E DISCUSSÃO}

Para a realização das análises foram utilizadas amostras de 30 secadores de mãos e cada amostra foram semeadas em 4 tipos de meios de cultura, EMB (Eosin Menthyilene Blue), Agar SS (Salmonella- Shiguella), Agar Manitol e Agar Sangue, totalizando 120 placas semeadas. Destas placas, foi observado crescimento microbiano em 99. Os dados de amostras de material e número de placas com e sem crescimento estão descritos na tabela 1.
As análises identificaram os seguintes microrganismos: Staphylococcus aureus, Staphylococcus coagulase-negativa, Bacillus sp., Streptococcus sp., Escherichia coli $e$ Pseudomonas aeruginosa, além do crescimento de fungos. Foi observado que, nas placas com ágar sangue, foi identificado $100 \%$ do crescimento de Staphylococcus aureus, ou seja, essa bactéria estava presente em todos os secadores de mãos utilizados no estudo. Ainda, pode-se verificar que em $83,3 \%$ das amostras ocorreu o crescimento de Streptococcus sp., em $56,7 \%$ das amostras ocorreu o crescimento de Staphylococcus coagulase-negativa, em $53,3 \%$ das placas ocorreu crescimento de microrganismos do gênero Bacillus sp., em $10 \%$ ocorreu um crescimento de $E$. coli e em 16,7\% ocorreu a presença de Pseudomonas aeruginosa.

O crescimento de fungo foi observado em algumas placas, porém, não houve processo de identificação da

Tabela 1: Quantidade de amostras utilizadas no estudo e quantidade de placas com e sem crescimento de microrganismos.

\section{Quantidade de amostras}

Secadores de mãos;

Placas semeadas

Placas com crescimento de microrganismos

Placas sem crescimento de microrganismos
30

120

99

Fonte: dados da pesquisa.

Tabela 2: Número placas que ocorreram o crescimento microbiano e o percentual do número de placas quando relacionado ao número de secadores de mãos utilizados no estudo.

Microrganismo encontrado
$\mathbf{N}^{\circ}$ de placas com crescimento do microrganismo
Relação entre o número de placas com crescimento do microrganismo e o número de secadores $(\%)$

\section{Staphylococcus aureus}

Streptococcus sp.

Staphylococcus coagulasenegativa.

\section{0}

25

17 
espécie, generalizando assim como Fungos, cresceram um total de 3 placas observadas e confirmadas por meios específicos e gram. A tabela 2 apresenta o número de placas que ocorreram o crescimento e o percentual do número de placas quando relacionado ao número de secadores de mãos utilizados no estudo.

Ainda, em relação aos parâmetros da presença de microrganismos relacionados aos banheiros de acordo com o gênero, pode-se verificar que, as amostras coletadas em banheiros femininos obtiveram apresentaram menos microrganismos quando comparado às amostras coletadas em banheiros masculinos. Foi observado que $82,2 \%$ das placas apresentam crescimento microbiano; destas, 76,8\% apresentaram resultados positivos e pertenciam a amostras coletadas em banheiro masculino (número de 64 placas) e $42 \%$ apresentaram microrganismos e pertenciam a amostras coletadas em banheiro feminino (número de 35 placas). 0 gráfico $1 \mathrm{~A}$ apresenta o percentual de placas com crescimento bacteriano em relação ao local de coleta.

O gráfico 1B apresenta a relação de crescimento entre Gram-positivas e Gram-negativas. Foi observado que um alto índice de proliferação de bactérias Gram-positivas representando quase a totalidade das bactérias encontradas (95\%).

A presença de microrganismos nos secadores, confirma a ideia de que existe um potencial microbiológico embutido no seu interior. $\mathrm{O}$ gráfico $2 \mathrm{~A}$ apresenta as formas Gram-positivas de cepas que cresceram ao serem semeadas. $O$ Staphylococus aureus foi o microrganismo que liderou no crescimento, pois das trinta placas de ágar manitol semeadas todas cresceram. A segunda bactéria gram-positiva que mais cresceu foi a Streptococcus sp., ocorreu o crescimento em $60 \%$ dos meios. Em 27, 7\% dos meios ocorreu o crescimento de Staphylococus coagulase negativa e em 6,7\% ocorreu o crescimento de Bacillus sp.

$\mathrm{O}$ gráfico 2B representa $\mathrm{O}$ crescimento de microrganismos Gram-negativos. Foram identificadas as bactérias Pseudomonas aeruginosa e Echerichia coli. Pode-se observar também que ocorreu um crescimento maior de Pseudomonas aeruginosa (6,7\% das placas) em relação a Echerichia coli (3,3\% das placas), que é um microrganismo de total relevância para interesse médico. Não foram feitas sorologias para identificação da espécie de Echerichia coli pois o objetivo foi apenas de identificação microbiana.

Os resultados mostraram que uma grande quantidade de bactérias estava presente em secadores de mãos de uso comum. O secador de mãos é o ambiente perfeito para o crescimento bacteriano, pois relata que o interior é quente e úmido sendo assim mais propício a essa contaminação, além de que estão alocados em toaletes, onde o ar é corriqueiramente povoado por microrganismos em propulsão aérea (SANTOS, 2011).

Gráfico 1: Porcentagem de placas com crescimento bacteriano em relação ao local de coleta e identificação dos tipos de bactérias

(A)

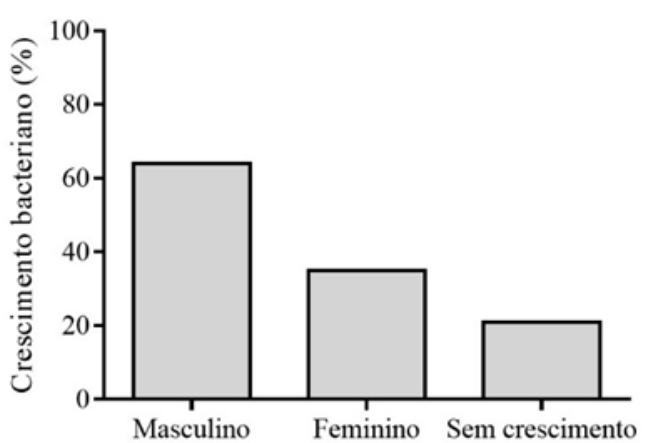

(B)

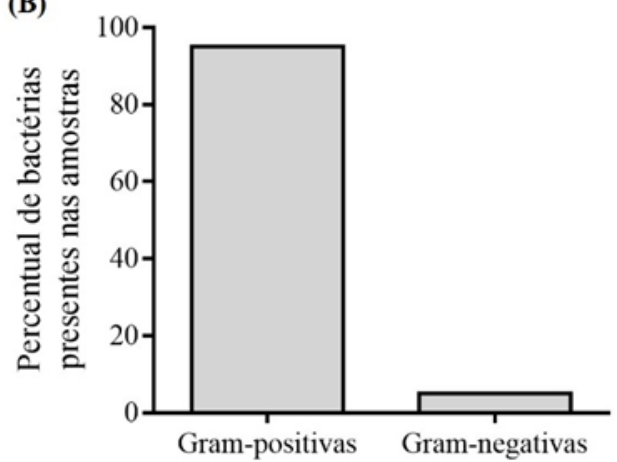

(A) Porcentagem de placas com crescimento bacteriano em relação ao local de coleta. (B) Porcentagem de bactérias Gram-positivas e Gram-negativas em relação ao número de placas com crescimento. Fonte: dados da pesquisa.

Não existem na literatura, até o presente momento, uma pesquisa de dados que partissem da premissa contrária ao estudo em relação ao crescimento bacteriano, apenas no fator econômico que, segundo Bezerra (2007) o secador de mãos é mais economicamente viável e sustentável do que o papel toalha.

Ramos, Filho e Lobo (2017) também observaram a contaminação dos secadores de mãos, para tanto, os autores semearam as placas e diferenciaram os microrganismos por métodos bioquímicos. Outro estudo realizado por Best, Parnell, Wilcox (2014), relataram o nível de crescimento microbiano nas mãos após secá-las no secador. Esses autores compararam o crescimento bacteriano quando comparado ao papel toalha e observaram um aumento de crescimento bacteriológico de 4,5 vezes ao secar nos equipamentos.

Em pesquisa realizada Lee et al. (2013) definiu a presença na contagem total de bactérias nos equipamentos públicos, visto que a presença da positividade nas placas oscila de equipamento para equipamento. O nível de contaminação 
reflete no tipo e na intensidade de uso dos mesmos. Nesta investigação, foi avaliada a presença de microrganismos durante o exercício da atividade do equipamento, observando-se uma contagem alta de placas crescidas nos secadores dos banheiros analisados.

Gráfico 2: Porcentagem de secadores onde houve presença de bactérias Gram-positivas e Gram-negativas

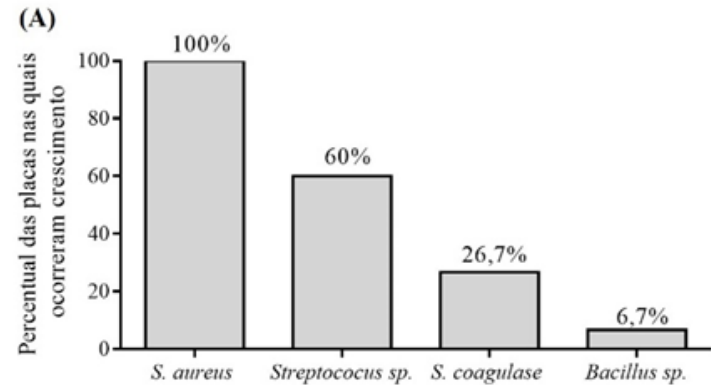

(B)

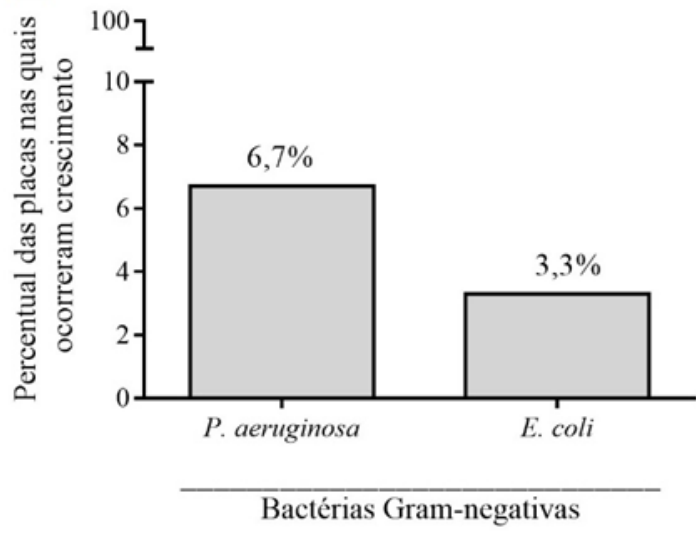

(A): Percentual de bactérias Gram-positivas que cresceram nas placas. (B): Percentual de bactérias Gram-negativas que cresceram nas placas. Fonte: dados da pesquisa.

Pode-se verificar também que nos banheiros masculinos os secadores de mãos estavam mais contaminados. Contudo, não foram encontrados dados na literatura que justificassem o crescimento de maior potencialidade nos banheiros masculinos e menor nos banheiros femininos. Acredita-se que a situação tenha relação com a higiene pessoal.

Nesse estudo foi demonstrado presença de bactérias gram-positivas e gram-negativas nos secadores de mãos. A $S$. aureus, bactéria gram-positiva, foi a espécie encontrada em todas as amostras. Esse gênero de bactérias pode provocar doenças de resolução mais simples, até doenças mais graves, como pneumonia, meningite e endocardite (SANTOS et al., 2007). As bactérias do gênero Streptococcus são responsáveis por doenças respiratórias (ANVISA, 2020), o gênero Bacillus pode ocasionar doenças diarreicas, sendo bastante associados à contaminação de alimentos (BARROS, 2004). Em relação às bactérias gram-negativas a $P$. aeruginosa foi a bactéria mais encontrada, elas estão relacionadas a infecções do trato respiratório, urinário e corrente sanguínea (GUERRA et al., 2006. Outra bactéria gram-negativa encontrada nas amostras foi a $E$. coli, que, caso se comporte como organismo oportunista, ocasiona doenças em hospedeiros suscetíveis e infecções em órgãos ou tecidos (SOUSA, 2006).

O tratamento de doenças bacterianas é realizado com o uso de antibióticos. A medida que um antibiótico é introduzido no mercado a sua utilidade clínica diminui até um ponto que ocorre um aumento na restrição do uso. Isso acontece pelo surgimento de cepas mais resistentes aos medicamentos (SANTOS et al., 2004). Neste sentido, o uso correto dos antibióticos associados a estratégias de redução de contaminação é fundamental para manutenção da qualidade de vida da população.

\section{CONCLUSÕES}

Nos últimos anos o uso de secadores de mãos elétricos tem se tornado cada vez mais comuns, contudo, poucos estudos sobre a análise microbiológica dos mesmos eram encontrados. Neste estudo foi verificado a presença de bactérias gram-positivas e gram-negativas presentes nas amostras.

A S. aureus estava presente em todos os secadores de mãos utilizados no estudo. Esta bactéria está presente na pele de pessoas saudáveis, contudo, quando comportandose de forma oportunista pode ocasionar doenças de quadros leves a graves. Foi verificado também, que os banheiros masculinos apresentavam maior incidência de bactérias nos secadores de mãos. Embora nenhum trabalho justifique o potencial crescimento de bactérias nesse local, acredita-se que este fator esteja relacionado à higiene pessoal.

Assim, pode-se concluir que existe um potencial de contaminação microbiológica nos secadores de mãos. A presença de bactérias de interesse médico mostra que o uso de secadores de mãos pode ser um potente meio de disseminação de microrganismos que podem ocasionar problemas à saúde dos indivíduos. Portanto, faz necessário cada vez mais investigar, através de metodologias quantitativas, a qualidade do uso desses equipamentos em banheiros de uso comum e consequentemente apresentar alternativas para a secagem das mãos nesses locais.

\section{REFERÊNCIAS}

ANVISA. Módulo 4 Gram-positivos. Disponível em: <http://www.anvisa.gov.br/servicosaude/controle/rede_r $\mathrm{m} /$ cursos/boas_praticas/modulo4/intr_ent.htm>. Acesso 
em: 18 jun. 2020.

BEST, E. L, PARNELL, P, WILCOX, M. H. Microbiological comparison of hand-drying methods: the potential for contamination of the environment, user, and bystander. Journal of Hospital Infection. v.88 n.4. p. 199-206, 2014.

BEZERRA, A. S. Análise da viabilidade econômica da substituição de papel toalha por secadores de mão elétricos em banheiros públicos. Revista de ciências do ambiente online, v.3 n.1, p.1-5. 2007.

BRASIL. portaria no 2616, de 12 de maio de 1998. Ministério da Saúde. Programa de Controle de Infecção Hospitalar. Brasília, DF. 1998.

ESPITIA, L. C. H. Deposition of Bacteria and Bacterial Spores by Bathroom Hot Air Hand Dryers. Applied and Eviromental Microbiology. v.1, n.1, p.5-34. 2018.

GUERRA et al.. Ocorrência de Pseudomonas aeruginosa em água potável. Acta Scientiarum. Biological Sciences. v. 28, n. 1, p. 13-18, 2006.

JONES, A. P. et al. Indoor air quality and health. Atmospheric Environment, v. 33, n. 28, p. 4535-4564, 2013.

LEE, K. ET AL. A test for the assessment of 'hygienic' hand disinfection using rotavirus. Journal of Hospital Infection, v. 24, n. 3, p. 201-210. 2013.

RAMOS, R. G.; FILHO, R. C. P.; LOBO, R. R. S. Análise da eficácia do secador elétrico ou toalhas de papel para enxugar as mãos. Revista Ciências do Ambiente On-Line, v.5, n.2, p. 2-4, 2017.

SANTOS et al.. A resistência bacteriana no contexto da infecção hospitalar. Enferm, v; 13, 2004.

SANTOS et al.. Staphylococcus aureus: visitando uma cepa de importância hospitalar. Jornal Brasileiro de Patologia e Medicina Laboratorial, v. 43, n. 6, p. 413-423, 2007.

SANTOS, A.A.M. Higienização das mãos no controle das infeções em serviços de saúde. Revista de Administração em Saúde. v. 4, n. 15, p.10-14. 2011.

SOUSA. Segurança alimentar e doenças veiculadas por alimentos: utilização do grupo coliforme como um dos indicadores de qualidade de alimentos. Revista APS, v.9, n.1, p. 83-88, 2006.

VIRTUOUS, T. I. Composição do ar. Virtuous Tecnologia da Informação. Disponível em: http://www.soq.com.br/conteudos/ef/ar/p1.php.2016. Acesso em:15 de Set. 2018.

Submissão: $21 / 06 / 2020$

Aprovado para publicação: 11/07/2020 